\title{
ModRule
}

\section{A user-centric mass housing design platform}

\author{
Tian Tian Lo ${ }^{1}$, Marc Aurel Schnabel ${ }^{2}$ and Yan $\mathrm{Gao}^{3}$ \\ ${ }^{1}$ The Chinese University of Hong Kong \\ skyduolgmail.com \\ ${ }^{2}$ Victoria University of Wellington \\ marcaurel.schnabelevuw.ac.nz \\ ${ }^{3}$ University of Hong Kong \\ yangao@hku.hk
}

\begin{abstract}
This paper presents a novel platform, ModRule, designed and developed to promote and facilitate collaboration between architects and future occupants during the design stage of mass housing buildings. Architects set the design-framework and parameters of the system, which allows the users to set their space requirements, budgets, etc., and define their desired way of living. The system utilizes gamification methodologies as a reference to promote incentives and user-friendliness for the layperson who has little or noarchitecturalbackground. This enhanced integration of a both bottom-up approach (user-centric/player) with atop-down approach (architectcentric/game-maker) will greatly influence how architects design high rise living. By bridging the gap between the architect and the user, this development aims to instill a greater sense of belonging to people, as well as providing architects with a better understanding of how to give people more control over their living spaces. The paper also presentsan evaluation of a design process that employed ModRule.
\end{abstract}

Keywords:Mass housing, collaborative design, participatory system.

Gabriela Celani, David M. Sperling and Juarez M.S. Franco (Eds.): The Next City: $16^{\text {th }}$ International Conference CAAD Futures 2015, pp. 325, 2015. @ Biblioteca Central Cesar Lattes 2015. 